\title{
Economic Burden of Hepatitis B Virus-Related Diseases: Evidence From Iran
}

\author{
Khosro Keshavarz ${ }^{1,2}$; Abbas Kebriaeezadeh ${ }^{1}$; Seyed Moayed Alavian ${ }^{3}$; Ali Akbari Sari ${ }^{1,4}$; Farid \\ Abedin Dorkoosh ${ }^{1}$; Maryam Keshvari ${ }^{5}$; Seyed Ali Malekhosseini ${ }^{6}$; Saman Nikeghbalian ${ }^{6}$; \\ Shekoufeh Nikfar ${ }^{1, *}$
}

${ }^{1}$ Department of Pharmacoeconomics and Pharmaceutical Administration, Faculty of Pharmacy, Tehran University of Medical Sciences, Tehran, IR Iran

${ }^{2}$ Health Human Resource Research Center, School of Management and Information Sciences, Shiraz University of Medical Sciences, Shiraz, IR Iran

${ }^{3}$ Baqiyatallah Research Center for Gastroenterology and Liver Diseases, Baqiyatallah University of Medical Sciences, Tehran, IR Iran

4 Department of Health Management and Economics, Tehran University of Medical Sciences, Tehran, IR Iran

5 Blood Transfusion Research Center, High Institute for Research and Education in Transfusion Medicine, Iranian Blood Transfusion Organization, Tehran, IR Iran

6 Blood Transfusion Research Center, High Institute for Research and Education in Transf

*Corresponding Author: Shekoufeh Nikfar, Department of Pharmacoeconomics and Pharmaceutical Administration, Faculty of Pharmacy, Tehran University of Medical Sciences, Tehran, IR Iran. Tel/Fax: +98-2188611883, E-mail: shekoufeh.nikfar@gmail.com

Received: December 9, 2014; Revised: February 16, 2015; Accepted: March 15, 2015

\begin{abstract}
Background: Hepatitis B infection is still the main cause of chronic liver disease in Iran, which is associated with significant economic and social costs.

Objectives: This study aimed to estimate the financial burden caused by CHB infection and its complications in Iran.

Patients and Methods: Prevalence-based and bottom-up approaches were used to collect the data. Data on direct medical costs were extracted from outpatient medical records in a referral gastroenterology and hepatology research center, inpatient medical records in several major hospitals in Tehran and Shiraz in 2013, and the self-reports of specialists. Data on direct non-medical and indirect costs were collected based on the patients' self-reports through face-to-face interviews performed in the mentioned centers. To calculate the indirect costs, friction cost approach was used. To calculate the total cost-of-illness in Iran, the total cost per patient at each stage of the disease was estimated and multiplied by the total number of patients.

Results: The total annual cost for the activate population of CHB patients and for those receiving treatment at various disease stages were respectively 450 million and 226 million dollars, with $64 \%$ and $70 \%$ of which allocated to direct costs respectively, and $36 \%$ and $30 \%$ to indirect costs respectively. The total direct costs alone for each group were respectively $1.17 \%$ and $0.6 \%$ of the total health expenditure. Furthermore, the cost spent on drugs encompasses the largest proportion of the direct medical cost for all stages of the disease.

Conclusions: According to the perspectives of payers, patients, and community, CHB infection can be considered as one of the diseases with a substantial economic burden; the disease, specifically in extreme cases, can be too expensive and costly for patients. Therefore, patients should be protected against more severe stages of the disease through proper treatment and early diagnosis.
\end{abstract}

Keywords: CHB; Cost of Illness; Diseases

\section{Background}

In recent decades, health expenditure has increased considerably worldwide. In addition, because of the skyrocketing costs of health related services, the health system of in Iran has faced significant challenges (1). These costs may be generated directly by medical diagnostic services or indirectly by the loss of productivity and quality of life (1). Hepatitis B virus (HBV) is now considered a serious problem for health all over the world (2) so that it is the most common and most important type of viral hepatitis and liver disease worldwide. It is subject to costly risks, high mortality, and morbidity, particularly in developing countries (3). Despite the availability of effective vaccines for HBV since the 1980s (4), it is estimated that still about 350 million people are suffering from chronic HBV infection (CHB) worldwide, which results in annually 500000 to 1.2 million deaths, of which $75 \%$ are Asian $(5,6)$. Hepa- titis B infection is the tenth leading cause of death in the world (7). The main cause of death from hepatitis B is various related conditions such as cirrhosis and hepatocellular carcinoma (HCC), which impose very high costs to patient and health system $(5,8,9)$. Thus, HBV infection is a serious health problem (10); for example, in the United States more than one billion united states dollars (USD) each year is spent due to hospitalization costs of patients with hepatitis B infection. Therefore, enormous economic and social costs are associated with this infection (11). As to the prevalence of this disease, with a prevalence of about $2 \%$, Iran is among the countries with moderate prevalence and fortunately, the country has approached those with lower prevalence rates $(1.5 \%)$ in recent years. Currently, about 1.2 million people in our country are infected with the virus (12), and if left untreated, about $15 \%$

Copyright (C) 2015, Kowsar Corp. This is an open-access article distributed under the terms of the Creative Commons Attribution-NonCommercial 4.0 International License (http://creativecommons.org/licenses/by-nc/4.0/) which permits copy and redistribute the material just in noncommercial usages, provided the original work is properly cited. 
to $40 \%$ of them are at risk of developing cirrhosis or HCC (12-14). As a result, it is estimated that 180000 to 480000 people are facing serious problems associated with HBV infection and require immediate attention (12). In Iran, there is no published study on the costs of $\mathrm{CHB}$ with comprehensive and simultaneous assessment of the direct and indirect costs of disease among patients with different states of the disease including compensated cirrhosis (CC), decompensated cirrhosis (DC), HCC, and liver transplantation (LT). However, in two studies, it has been shown that the economic burden of hepatitis can be significant for the community $(15,16)$. The economic burden of $\mathrm{CHB}$ on communities and individuals in the country is unknown because of insufficient evidence. The provision of accurate data on the economic burden of HBV infection can help healthcare policymakers to make appropriate decisions about the prevention and treatment of this disease (17). Considering the significance of the burden of HBV infection in the world and Iran on one hand, and the lack of a comprehensive economic analysis of the disease in the country on the other hand, doubled the need for conducting this study.

\section{Objectives}

The aim of this study was to estimate direct and indirect costs of various states of CHB in the country.

\section{Patients and Methods}

This descriptive analytical study was conducted in 2013 as a cross-sectional study on the patients with CHB who were referred to the Gastroenterology And Hepatology Research Center, Baqiyatallah University of Medical Sciences, Tehran, Iran, which is a referral center and the core of hepatitis network in the country, and also Nemazee Hospital, Shiraz University of Medical Sciences, Shiraz, Iran, whose liver transplantation center is the main treatment hub of the country. This study aimed to evaluate direct medical and non-medical costs and indirect costs from the societal perspectives. The process of analyzing the costs of $\mathrm{CHB}$ was performed in three parts as follows:

A) The first part determined and estimated the direct costs imposed on patients with CHB at its different stages.

B) The second part was devoted to evaluation and estimation of indirect costs.

C) In the third part, using a combination of data obtained from the two previous parts, an estimate was made, which was multiplied by the number of patients with $\mathrm{CHB}$ at its various stages to calculate the overall financial burden of the disease in the country.

To obtain information about costs, prevalence-based approach was used. For the analysis of the costs of disease, this study adopted bottom-up approach (18).

\subsection{Part 1: Measurement of Direct Medical Cost}

To increase the accuracy and precision of data collection on direct medical costs, we tried to use the patients and specialists' viewpoints and inpatient and outpatient medical records simultaneously from January 1, 2013 through December 31, 2013. To estimate the costs at different stages of the disease, the patients were classified into five groups as follows: CHB, CC, DC, HCC, and LT.

Charges do not reflect true costs due to government subsidies for medicines and hospital services; therefore, we used private cost as an indicator of measuring cost (19). To obtain a more accurate estimate of the cost analysis in patients with $\mathrm{CHB}$ and its different stages, we attempted to calculate the total direct cost of medication, visit, hospitalization, diagnostic tests, etc. separately for patients in different stages, based on the non-subsidized price in 2013.

\subsubsection{Calculation of Direct Medical Cost}

The mean of total annual direct medical costs $(15,20,21)$ per patient in each of the different stages of HBV infection was calculated separately as follows:

The total annual cost per patient in each disease state $=$ (Average number of visits per year $\times$ visit tariffs) + (average number of tests per year $\times$ tariffs for each test $)+($ average number of diagnostic services per year $\times$ tariffs for each diagnostic service) + (average number of hospitalizations per year $\times$ tariffs for each day of hospitalization) + (the cost of every unit of medicine $\times$ the number of prescribed medicines on a course of treatment)

It is worth mentioning that the percentage of the prevalence of medical care utilization, under the supervision of specialists, was taken into account while calculating all items.

Moreover, in this study, 2013 tariffs with the currency of USD and an exchange rate of 26668 IRR for each USD (22) were used to calculate direct costs.

\subsubsection{Measurement of Direct Non-Medical Cost}

To estimate the related costs, we used the patient's selfreport during the study period. Because the vast majority of patients referred to the mentioned treatment centers were living outside Tehran and Shiraz, items such as travel time, costs of travel to these centers to receive health care, and accommodation and meals costs were considered as important components of direct non-medical costs.

\subsubsection{Calculation of Direct Non-Medical Cost}

The average of the total annual direct non-medical costs $(15,20,21)$ per patient in each of different stages of HBV infection was calculated separately as follows:

The average cost per patient in each disease state $=$ Number of referrals for medical services per year $\times$ Cost of each visit $\times$ percentage of patients referred from other cities

\subsection{Part 2: Measurement of Indirect Cost}

Cost data were collected via face-to-face or telephone 
interviews with patients who were receiving inpatient and outpatient services from the mentioned treatment centers during the study period. Moreover, the informed consent was obtained from all patients.

\subsubsection{Calculation of Indirect Cost}

To calculate the cost of productivity loss due to presenteeism and absenteeism, we used Friction cost approach (23).

To calculate the indirect costs imposed on patients with DC and HCC the following formula was used:

Disabled patients $=$ average monthly income $\times 12 \times$ (number of employed persons/total sample) $\times 0.8 \times 20.3 \%$ $\times 5$.

In friction cost approach, we considered an elasticity of 0.8 between production and work force, labor productivity of $20.3 \%$ in Iran, and the interval of five months.

To calculate the indirect costs of CC and CHB, the following formula was used:

Employed patients $=$ average monthly income $\times 12 \times$ (number of employed persons/total sample) $\times 0.4 \times 20.3 \%$ $\times 3$.

\subsection{Part 3: Financial Burden Imposed on All Pa- tients With Chronic Hepatitis B at Its Different Stages}

After estimating direct and indirect costs for every stage of disease separately, two types of financial burden were estimated for every stage of the disease:

A) First, after collection of data about the prevalence rate of the disease, the population of the country, and the average cost of each stage of disease, the potential financial burden of the disease in patients in the country was calculated using the following formula:

Financial Burden $=$ Total cost $($ direct medical + direct non-medical + and indirect costs $) \times$ estimated number of infected subjects in Iran

B) In order to calculate more accurately, we attempted to estimate the costs of treatments for patients with $\mathrm{CHB}$ in different stages of the disease. Accordingly, to calculate the real costs imposed on health system due to this disease per year, the average number of patients treated per year for each disease state separately was estimated and multiplied by the cost of the disease for each stage of the disease.

The total annual cost imposed on treated patients with each disease stage $=$ the average number of patients treated $\times$ the average cost imposed on a patient.

\subsection{Estimation of Prevalence}

Given that the reliable prevalence data of different stages of HBV was not readily available for many countries (20), we used information from various sources to estimate the prevalence. According to Poorolajal and Majdzadeh study, the overall prevalence of CHB in Iran was estimated at approximately 1.7\% (24). According to the latest figures released by the Office for Prevention of Viral Hepatitis in the Ministry of Health and Medical Education, the prevalence of HBV in Iran is estimated to be about $1.5 \%$. Therefore, considering an estimated population of 78 million people in Iran in 2014 (25), the total number of HBV carriers was estimated to be 1.17 million people. Of these, approximately $80 \%$ are inactive population and $20 \%$ are active population with CHB. Hence the active population is 234000 people in the country; hence, $80 \%$ are patients with $\mathrm{CHB}$ (187200 people) and about $20 \%$ are patients with liver cirrhosis (46800 people). According to database of the national hepatitis network and the statistics about the chronic patients presented by Gastroenterology And Hepatology Research Center in Baqiyatallah University of medical Sciences, the ratio of patients with CC to DC is 4:1; hence, the number of patients with CC and DC in the country are about 37440 and 9360 people, respectively.

Moreover, since there was no data available in the country about the incidence of the disease among patients with HCC, we used a published study, which reported its mortality rate to be about 3.53 per 100000 people (26), to estimate the incidence. Therefore, the incidence was estimated as follows (20):

Prevalence $(\mathrm{P})=$ incidence $(\mathrm{I}) \times$ average duration of illness (D)

Based on experts' opinion, the average survival rate in patients with HCC in Iran is about a year (the Hepatitis Research Network of the country). Thus, under these conditions, the rate of prevalence is equal to the rate of incidence. Given that the mortality rate for HCC cases includes the incidence cases and as the disease duration in the country is expressed per year, it can be stated that the incidence is equal to deaths in the country. Therefore, in a population of 78000000 people, there are approximately 2753 cases of liver cancer per year; taken into consideration that $80 \%$ of liver cancer cases are due to $\mathrm{CHB}$ (26), about 2203 HBV and HCC occur in the country per year. Nowadays, on average about 500 liver transplants are performed annually in the country, 90\% of which are done in Shiraz Transplant Center. So far, about 3000 transplants have been performed in the country of which about 553 transplants (20\%) have been due to CHB. Thus, according to the estimations based on the above data, on average, about 111 liver transplants due to HBV infections are performed annually. In addition, to accurately estimate the true costs imposed on patients with HBV in the country, we tried to estimate the average number of patients receiving treatment per year for patients with $\mathrm{CHB}$ in different stages of disease. Therefore, based on experts' opinion, about $20 \%$ of patients with $\mathrm{CHB}$, which is equal to 37440 persons, in the country are currently receiving treatment. Moreover, according to the views of gastroenterology specialists, all patients with cirrhosis (46800) and liver cancer (125 patients) receive treatment.

To generalize the results of this study to the whole coun- 
try, we tried to multiply the calculated cost values by the estimated incidence of HBV infection in different stages of the disease. However, since there is no general agreement about the total number of patients with hepatitis in the country, we attempted to estimate the average incidence of the disease via reviewing different published reports.

\subsection{Sensitivity Analysis}

The one-way sensitivity analysis was performed for the estimated costs. In sensitivity analysis, the fixed cost components and the number of patients in different stages of CHB were changed as follows:

A) The prevalence rates of patients with HBV infection from $1.3 \%$ to $3.8 \%$ (27)were used as lower and upper limits ( $95 \% \mathrm{CI})$, respectively, to estimate the number of carriers of HBV, CHB, CC, and DC.

B) The prevalence rates of 2.77 and 4.26 per 100000 population of males and females (26) were used as the lower and upper limits, respectively, to estimate the incidence of HCC in patients.

\section{Results}

In this study, 280 patients at different stages of the disease (130 patients with CHB, 56 with CC, 71 with DC, and 23 with HCC) were enrolled. Table 1 briefly presents the descriptive results, classified by the stages of the disease based on sex, education, occupational status, and the mean age of the patients. According to Table 1, the mean age of the entire sample in all states of the disease was 47 years (range, $43.45-54.7$ years) and $70 \%$ of the patients were male.

Table 1. Socio-Demographic Characteristics of Patients With Chronic Hepatitis B Infection in Different Disease Stages in Iran ${ }^{\text {a }}$

\begin{tabular}{|c|c|c|c|c|c|}
\hline \multirow[t]{2}{*}{ Variable } & \multicolumn{5}{|c|}{ Stage of Disease } \\
\hline & CHB & $\mathrm{CC}$ & DC & HCC & No. \\
\hline Total number of patients & 130 & 56 & 71 & 23 & 280 \\
\hline Male & 87 & 38 & 53 & 18 & 196 \\
\hline Female & 43 & 18 & 18 & 5 & 84 \\
\hline Non Academic & 98 & 11 & 11 & 16 & 135 \\
\hline Academic & 33 & 45 & 60 & 7 & 145 \\
\hline Employed & 77 & 31 & 27 & 10 & 145 \\
\hline Unemployed & 53 & 25 & 44 & 13 & 135 \\
\hline The mean age & 43.45 & 48 & 50.5 & 54.7 & 47 \\
\hline
\end{tabular}

a Abbreviation: CC, compensated cirrhosis; CHB, chronic hepatitis B infection; DC, decompensated cirrhosis; and HCC, hepatocellular carcinoma.

Table 2. Average Annual Direct Medical and Non-Medical Costs Per Patient With Chronic Hepatitis B Infection Based on Various Stages of the Disease, $2013^{\mathrm{a}, \mathrm{b}}$

\begin{tabular}{|c|c|c|c|c|c|c|c|c|}
\hline Type of Service & CHB, USD & Percentage & CC, USD & Percentage & DC, USD & Percentage & HCC, USD & Percentage \\
\hline \multicolumn{9}{|l|}{ Direct medical costs } \\
\hline Visits to the doctor & $49 \pm 7.23$ & 8 & $49 \pm 7.23$ & 5 & $99 \pm 37.09$ & 2 & $391 \pm 96.42$ & 4 \\
\hline Tests & $342 \pm 13.81$ & 52 & $354 \pm 9.25$ & 36 & $403 \pm 9.6$ & 10 & $536 \pm 30.43$ & 5 \\
\hline Diagnostic services & $82 \pm 24.17$ & 12 & $124 \pm 31.41$ & 13 & $1060 \pm 171.66$ & 25 & $2,195 \pm 198.39$ & 22 \\
\hline Drug & $188 \pm 141.07$ & 28 & $455 \pm 286.21$ & 46 & $1554 \pm 915$ & 37 & $4,418 \pm 797$ & 44 \\
\hline Hoteling & - & - & - & - & $1063 \pm 580.42$ & 26 & $1,417 \pm 601.12$ & 14 \\
\hline Other health services & - & - & - & - & - & - & $1,116 \pm 470.50$ & 11 \\
\hline Total & 662 & & 982 & & 4179 & & 10072 & \\
\hline \multicolumn{9}{|l|}{ Direct non-medical costs } \\
\hline Transportation & $96 \pm 39.52$ & 47 & $96 \pm 39.52$ & 47 & $288 \pm 73.88$ & 20 & $288 \pm 73.88$ & 20 \\
\hline Meals & $36 \pm 16.23$ & 18 & $36 \pm 16.23$ & 18 & $378 \pm 101.28$ & 27 & $378 \pm 101.28$ & 27 \\
\hline Accommodation & $72 \pm 33.88$ & 35 & $72 \pm 33.88$ & 35 & $756 \pm 192.07$ & 53 & $756 \pm 192.07$ & 53 \\
\hline Total & 204 & 100 & 204 & 100 & 1422 & 100 & 1422 & 100 \\
\hline Total costs & 866 & & 1186 & - & 5600 & - & 11494 & - \\
\hline
\end{tabular}

${ }^{\mathrm{a}}$ Abbreviations: CC, compensated cirrhosis; CHB, chronic hepatitis B infection, DC; decompensated cirrhosis; HCC, hepatocellular carcinoma; USD, the united States dollar.

$\mathrm{b}$ Data are presented as mean $\pm \mathrm{SD}$. 


\subsection{Direct Medical and Non-Medical Costs}

Based on data extracted from the mentioned centers, $80 \%$ of the patients were from other cities and $20 \%$ lived in Tehran and Shiraz. This point was considered in the estimation of direct non-medical costs. Table 2 presents the annual costs of utilization of treatment and diagnostic services (direct medical costs) and the costs of other services required to receive healthcare services (direct non-medical costs) for CHB per patient for each stage of the disease. As shown, the minimum cost (about 866 USD) was observed in patients with CHB and the maximum cost (11494 USD) in patients with HCC. Table 2 also shows that the annual direct medical costs of treatment increased with disease progression. In all cases, except for patients with $\mathrm{CHB}$, the costs of medicine accounted for the greatest share of healthcare costs so that $46 \%, 37 \%$, and $44 \%$ of direct health care costs were spent on drugs required for CC, DC, and HCC stages, respectively. It covered $28 \%$ of the costs in patients with CHB. The cost of the test, which is $52 \%$, has the greatest share of healthcare costs in patients with CHB.
Non-direct medical costs: Because many patients come from neighboring provinces, and their travel time is often a full working day or more, the costs of travelling, meals, especially accommodation, increases with progression of the disease to more severe stages (Table 2). Table 3 presents the estimated costs of medical and diagnostic services (direct medical costs) as well as the costs of other services needed to receive medical care (direct non-medical costs) and to undergo liver transplantation in patients with cirrhosis and liver cancer caused by HBV per patient; it is estimated to cost more than 36994 USD.

\subsection{Indirect Costs}

In our cost survey, none of the participants with $\mathrm{CHB}$ and CC had to lose their own job to receive care for disease complications. As the results of the study showed, it seems that these elements had negligible effect on indirect costs for this group of patients. As it is shown, like the rest of the costs, indirect annual treatment costs increases with the progression of the disease, and indirect costs for LT patients have the greatest share of health care costs, which is about 3223 USD (Table 4).

Table 3. Average Direct Costs of Liver Transplantation Per Patients With Cirrhosis and Liver Cancer Caused Due to Hepatitis B Virus in Iran, 2013

\begin{tabular}{|c|c|}
\hline Type of Cost & Cost, USD \\
\hline \multicolumn{2}{|l|}{ Before surgery } \\
\hline Preoperative counseling and examinations & 1803 \\
\hline Diagnostic and laboratory services & 2697 \\
\hline Total costs of the examinations before admission & 4500 \\
\hline \multicolumn{2}{|l|}{ Operating room costs } \\
\hline Cost of surgery \& anesthesia & 9375 \\
\hline Costs of anesthesia drugs and materials & 2904 \\
\hline Costs of operating room consumable materials & 2705 \\
\hline The total cost of the operating room & 14984 \\
\hline \multicolumn{2}{|l|}{ Hospitalization costs } \\
\hline Hospitalization costs associated transplant ICU hoteling and services & 3360 \\
\hline Costs associated transplant ward hoteling and services & 3023 \\
\hline Cost of the drugs consumed in the ward & 4406 \\
\hline Cost of the consumable materials in the ward & 3221 \\
\hline Cost of tests during admission & 1678 \\
\hline Total costs of hospitalization & 15688 \\
\hline \multicolumn{2}{|l|}{ Cost of post-discharge follow-up } \\
\hline Examinations, counseling, and actions after patient discharge & 686 \\
\hline \multicolumn{2}{|l|}{ Accommodation expenses for one month after discharge } \\
\hline Assuming $85 \%$ of people as non-resident & 574 \\
\hline \multicolumn{2}{|c|}{ Meals and travelling costs during operation and after discharge for one month } \\
\hline Assuming $85 \%$ of people as non-resident & 562 \\
\hline Total costs & 36994 \\
\hline
\end{tabular}


Table 4. Estimated Average Direct Medical and Non-Medical Costs, Indirect Costs, Total Costs, and the Ratio of Direct to Indirect Costs of Chronic Hepatitis B Infection Per Patient Based on Various Stages of the Disease in Iran, 2013 a,b

\begin{tabular}{lcccccc}
\hline ID & Cost & CHB, USD & CC, USD & DC, USD & HCC, USD & LT \\
\hline $\mathbf{1}$ & DMC & $662(44)$ & $982(55)$ & $4179(57)$ & $10072(76)$ & $35858(86)$ \\
$\mathbf{2}$ & DNMC & $204(13)$ & $204(11)$ & $1422(19)$ & $1422(11)$ & $2647(6)$ \\
$\mathbf{3}$ & IC $^{\text {C }}$ & $649(43)$ & $607(34)$ & $1765(24)$ & $1721(13)$ & $3223(8)$ \\
$\mathbf{4}$ & DC to IC Ratio & $1.3: 1$ & $2: 1$ & $3.2: 1$ & $7.6: 1$ & $12: 1$ \\
& Total Cost & $1515(100)$ & $1793(100)$ & $7366(100)$ & $13215(100)$ & $41728(10)$ \\
\hline
\end{tabular}

\footnotetext{
a Abbreviations: CC, compensated cirrhosis; CHB, chronic hepatitis B; DC, decompensated cirrhosis; DC to IC Ratio, ratio of direct cost to indirect costs; DMC, direct medical cost; DNMC: direct non-medical cost; HCC, hepatocellular carcinoma; IC, indirect costs; LT, liver transplantation; and USD, the United States dollar.

b Data are presented as No.(\%).

C Annual indirect costs caused by presenteeism and absenteeism based on friction cost approach.
}

Table 5. Estimated Average Direct medical and Non-Medical Costs, Indirect Costs, Total Costs and the Ratio of Direct to Indirect Costs of Chronic Active Hepatitis B patients in Iran, 2013 ${ }^{\text {a }}$

\begin{tabular}{|c|c|c|c|c|c|c|c|}
\hline $\begin{array}{l}\text { Disease } \\
\text { Category }\end{array}$ & Number of Patients & Patient's Condition & DMC, USD & DNMC, USD & IC, USD & COI, USD & DC to IC Ratio \\
\hline \multirow[t]{3}{*}{ CHB } & & & & & & & $1.33: 1$ \\
\hline & 184,886 & Total number of $\mathrm{CHB}$ patients & 122394532 & 37716744 & 119991014 & 280102290 & \\
\hline & 36977 & Under treatment & 24478774 & 7543308 & 23998073 & 56020155 & \\
\hline CC & 37440 & Under treatment & 36766080 & 7637760 & 22726080 & 67129920 & $1.95: 1$ \\
\hline DC & 9360 & Under treatment & 39115440 & 13309920 & 16520400 & 68945760 & $3.17: 1$ \\
\hline HCC & 2203 & Under treatment & 22188616 & 3132666 & 3791363 & 29112645 & $6.68: 1$ \\
\hline LT & 111 & Under treatment & 3980238 & 293817 & 357753 & 4631808 & 12.00:1 \\
\hline \multicolumn{8}{|l|}{ Total } \\
\hline & 86091 & Under treatment & 126529148 & 31917471 & 67393669 & 225840288 & $2.35: 1$ \\
\hline & 234000 & Considering all active patients & 224444906 & 62090907 & 163386610 & 449922423 & $1.75: 1$ \\
\hline
\end{tabular}

a Abbreviations: CC, compensated cirrhosis; COI, cost of illness; DC, decompensated cirrhosis; CHB, chronic hepatitis B; DMC, direct medical cost; DNMC, direct non-medical cost; HCC, hepatocellular carcinoma; IC, indirect costs; LT, liver transplantation; and USD, the United States dollar.

\subsection{Financial Burden of Direct Medical and Non- Medical Costs and Indirect Costs for Chronic Hepa- titis B Infection in Iran}

Based on estimated prevalence, the active and inactive population of patients, the numbers of people receiving treatment in a year, and direct medical costs for different stages of $\mathrm{CHB}$ were calculated via the aforementioned methods and the results are presented in Table 5. Since $20 \%$ of chronic carriers are the active population of the country, direct medical costs for different stages of disease among active hepatitis population was estimated at about 224444906 USD (Table 5). Finally, to estimate actual medical costs occurred in a year due to HBV for different stages of disease, the share of patients receiving treatment from the active population with $\mathrm{HBV}$ infection was determined to be 126529148 USD (Table 5). The total direct non-medical costs for different stages of disease among active hepatitis population and patients receiving treatment were approximately estimated at 62090907 and 31917471 USD, respectively (Table 5). The total indirect costs of different stages of disease for active population with HBV infection and in patients receiving treatment were estimated at 163386610 and 67393669 USD, respectively (Table 5).

\subsection{Estimated Total Cost of Illness for Chronic Hep- atitis $B$ Infection in Iran}

Figure 1 Table 4 present a summary of the direct medical costs, direct non-medical costs, and the ratio of indirect costs to direct costs per patient and for different stages of disease in Iran. The total cost of CHB for different stages of the disease among the active hepatitis B population and patients receiving treatment in the country were calculated as 449922423 and 225840288 USD, respectively. In addition, the ratio of direct to indirect costs increases with the progress of the disease (Table 5). The results showed that the direct medical costs are the main component of the total cost of treating patients with HBV infection and encompasses about $64 \%$ and $70 \%$ of the costs for active hepatitis B population and patients receiving treatment, respectively. 
Keshavarz Ket al.

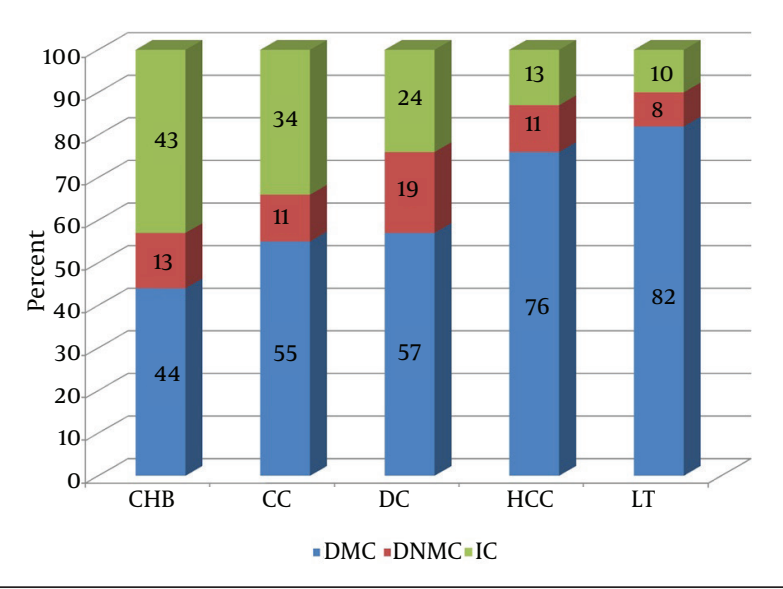

Figure 1. Direct Medical Costs, Direct Non-medical Costs, and Indirect Costs as a Percentage of Total Cost for Each Group of Patients

\subsection{Financial Burden of Illness Survey}

A total of 280 patients with a mean age of 47 years (range, 43 - 55 years) with different stages of disease participated in the study among which $70 \%$ were male. Moreover, 94 persons had DC and HCC; when this group of patients with liver disease were asked "Whether they have had to spend their own or their family members saving or loans to provide their medical cost in the last one year?" almost all of the participants (approximately 96\%) expressed their concerns about the high cost of the disease, especially in drugs and tests. Due to the high financial burden of the disease (range, 7500-75000 USD), many of the patients were obliged to borrow from relatives, sell their assets, or get a loan, and consequently, their treatment had greatly influenced their household income. Of all participants with CHB and CC (186 patients), about
$30 \%$ were forced to get a loan or spend their savings; however, it was more common among patients with CC. Most patients with $\mathrm{CHB}$ ( $80 \%$ ) had not been forced to borrow money due to the disease expenses. It should be noted that the effect of the disease on the psychologic aspects of the patient and all family members, especially in severe cases of disease, is considerable; almost all the participants with severe stages of the disease (over 90\%) expressed this concern.

\subsection{Sensitivity Analysis}

Table 6 presents the results of one-way sensitivity analysis for direct medical costs, direct non-medical costs, indirect and total costs of CHB for different stages of the disease (where the number of patients is variable and cost components are fixed). The results also showed that direct to indirect cost ratio is fixed by changing the number of patients. It indicates the robustness of the results.

\section{Discussion}

This study was the first comprehensive study on the cost of illness among hepatitis patients in Iran; it tried to estimate the direct and indirect costs of $\mathrm{CHB}$ and its related complications at the national level. The present study showed that $\mathrm{CHB}$ and its associated complications can impose a considerable financial burden on the country's health system and community in general; in this regard, the present study is in line with the study of Kalantari et al. in which the researchers only calculated the direct costs of the mentioned disease (1). The total annual costs for the population of active $\mathrm{CHB}$ and patients receiving treatment were respectively 450 million USD (range, 387 million to 1103 million USD) and 226 (range, 192 million to 532 million USD); the obtained result was not consistent with the results of two previously studies in the

Table 6. Sensitivity Analysis for Direct Medical and Non-Medical Costs, Indirect Costs and Total Costs of Chronic Hepatitis B Infection in Iran, $2013^{\mathrm{a}}$

\begin{tabular}{|c|c|c|c|c|c|c|}
\hline $\begin{array}{l}\text { Disease } \\
\text { Category }\end{array}$ & $\begin{array}{c}\text { Estimated } \\
\text { Number of Pa- } \\
\text { tients, Range }\end{array}$ & $\begin{array}{l}\text { DMC (One-Way Sensi- } \\
\text { tivity Analysis),USD }\end{array}$ & $\begin{array}{c}\text { DNMC (One-Way } \\
\text { Sensitivity Analy- } \\
\text { sis), USD }\end{array}$ & $\begin{array}{l}\text { IC (One-Way Sensitiv- } \\
\text { ity Analysis), USD }\end{array}$ & $\begin{array}{l}\text { COI (One-Way Sensi- } \\
\text { tivity Analysis), USD }\end{array}$ & $\begin{array}{l}\text { DC to IC } \\
\text { Ratio }\end{array}$ \\
\hline \multicolumn{7}{|l|}{ CHB } \\
\hline & $160416-471301$ & $106195392-312001262$ & 32724864 - 96145404 & $104109984-305874349$ & $243030240-714021015$ & 1.33:1 \\
\hline & $32083-94260$ & 21239078 - 62400252 & $6544973-19229081$ & $20821997-61174870$ & $48606048-142804203$ & \\
\hline CC & $32448-94848$ & 31863936 - 93140736 & 6619392 - 19348992 & $19695936-57572736$ & $58179264-170062464$ & $1.95: 1$ \\
\hline DC & $8112-23712$ & 33900048 - 99092448 & 11535264 - 33718464 & $14317680-41851680$ & $59752992-174662592$ & $3.17: 1$ \\
\hline HCC & $1728-2658$ & $17404416-26771376$ & $2457216-3779676$ & 2973888 - 4574418 & $22835520-35125470$ & $6.68: 1$ \\
\hline LT & $96-281$ & $3442368-10076098$ & $254112-743807$ & 309408 - 905663 & $4005888-11725568$ & $12: 1$ \\
\hline \multicolumn{7}{|l|}{ Total } \\
\hline & $74467-215759$ & 107849846 - 291480910 & $27410957-76820020$ & $58118909-166079367$ & $193379712-531745922$ & $2.26: 1$ \\
\hline & $202800-592800$ & $192806160-541081920$ & $53590848-153736343$ & $141406896-410778846$ & $387803904-1105597109$ & $1.72: 1$ \\
\hline
\end{tabular}

\footnotetext{
a Abbreviations: CC, compensated cirrhosis; COI, cost of illness; DC, decompensated cirrhosis; CHB, chronic hepatitis B; DMC, direct medical cost; DNMC, direct non-medical cost; HCC, hepatocellular carcinoma; IC, indirect costs; LT, liver transplantation; and USD, the United States dollar.
} 
country $(1,15)$, because they only calculated the prevalence among chronic carriers in the estimation of costs for patients with $\mathrm{CHB}$; moreover, unlike the standards used in this study, they have made no distinction between the inactive population, active population, and those receiving treatment. Therefore, they overestimated the costs $(1,15)$. Of this amounts, respectively $64 \%$ and $70 \%$ have been assigned to the direct costs. The total direct cost alone was roughly equal to $1.17 \%$ (range, $1 \%-2.83 \%$ ) and $0.6 \%$ (range, $0.5 \%-1.5 \%$ ) of total health costs in 2013 . The total health system cost in Iran in 2013 was 24471951402 billion USD, which was equal to $6.6 \%$ of gross domestic product (GDP) (28). Among the active population and patients receiving treatment at different stages of $\mathrm{CHB}$, patients with $\mathrm{CHB}$ and cirrhosis, respectively, had caused the largest share of direct costs to the health system in Iran. Compared to patients with $\mathrm{CHB}$, a patient with $\mathrm{LT}$ ) or HCC impose respectively 31-times and 12-times higher burden of health costs to the community. It might be due to the higher number of patients with $\mathrm{CHB}$ and cirrhosis compared with patients with LT or patients with HCC. In view of the mentioned fact, this study is consistent with the study of Ong et al. (20), which was conducted in Singapore. In this study, the cost of medicines had the largest share among the direct medical costs for all stages of the disease, especially CC, DC, and HCC; it includes about half of the direct medical costs and is considered as a major problem for patients. In a study by Tu et al. which was conducted on a cost of illness among patients with $\mathrm{CHB}$ in Vietnam in 2012, medical costs were reported as the major item among direct medical costs (21). Thus, in general, our results were similar to the results reported from other countries, which showed the increase of direct cost is line with disease progression (29-32).

In addition, the indirect costs of active $\mathrm{CHB}$ and patients receiving treatment for $\mathrm{CHB}$ at different stages encompassed $36 \%$ and $30 \%$ of total costs, respectively. In other published studies, almost one-third of the costs were attributed to indirect costs and as the disease progresses; hence, the direct costs to indirect costs ratio was increased $(15,20)$. These results suggest that the indirect costs are an important cost component in the estimation of total costs caused by CHB. Because governmental supports provide only one-third of the financial burden of healthcare and the remaining two-thirds (55\% - 65\%) is provided by out of pocket payments in Iran (33), this can be very disturbing and important. Therefore, this study showed that $\mathrm{CHB}$ with a prevalence rate of $1.5 \%$ among chronic carriers (1.17 million people) in the absence of proper management of the disease can put $15 \%$ to $40 \%$ (i.e., approximately 175500 to 468000 people) at risk of developing cirrhosis or HCC (12-14), It will impose the average cost of 982 million to2620 million USD on community and the health system, which will lead to four-times to 12-times higher costs than the current costs imposed on patients receiving treatment. Therefore, a considerable financial burden will be imposed on the health system and society, and stops or slows the effective treatment of liver disease.

Similar to other published studies $(20,21)$; this study demonstrated that severe disease states, including DC and HCC are very expensive for patients. When patients were asked whether they had to spend their own or their family members' saving or loans, almost all participants with more severe stages of disease, including DC, HCC, and LT, said they were forced to get a loan or borrow from friends. They also said that the disease had imposed heavy financial burden on patients and their families, and most of them had many difficulties to cover the cost of treatment. The problem is more significant for services that are not covered by insurance, such as certain medications or receiving services from nongovernmental centers (34), and is considered as a catastrophic cost. Considering the abovementioned problems, it should be tried to prevent the progress of disease to more severe stages via proper and timely diagnosis and treatment. On the other hand, because only the overall prevalence rate of chronic carriers had been taken into account for calculating the costs in the two previous studies conducted in Iran $(1,15)$, it had led to an overestimation of the disease costs. In this study, we tried to resolve this issue. In fact, the active and inactive population as well as patients receiving treatment was identified distinctively and their costs were estimated to calculate the actual current cost of the disease in the country. Because the Hepatology and Gastroenterology Research Center of Baqiyatallah University in Tehran and the Liver Transplantation Center of Nemazee Hospital in Shiraz are among the main referral centers in the country, the cost estimates in this study can provide a good estimate of the true cost in patients with CHB in Iran. Hence, the results can be used by health policymakers to plan and assign the resources more effectively.

One limitations of this study was the lack of documentary evidence about the exact number of patients with $\mathrm{CHB}$ receiving treatment in different stages as well as the prevalence of HCC in the Iran. As a result, in this study, we used the opinions of some of the best specialists in this field. In conclusion, due to the chronic nature of the disease, the management of patients with HBV infection is not only a therapeutic challenge, but also a method for the prevention of considerable economic burden of disease from the perspective of the payer, patient, and community. Therefore, patients should be protected against more severe stages of the disease through proper treatment and early diagnosis. This can be an important message for policymakers and administrators of healthcare system.

\section{Acknowledgements}

This study was part of a PhD thesis in the field of Pharmacoeconomics and Pharmaceutical Administration in Faculty of Pharmacy, Tehran University of Medical Sciences. The authors would like to thank Center for Develop- 
ment of Clinical Research of Nemazee Hospital, Faculty of Management and Medical Information Sciences in Shiraz University of Medical Sciences and Dr. Nasrin Shokrpour for editorial assistance, and also Sheida Ebrahimi and Maryam Gholami for their cooperation in the research.

\section{Authors' Contributions}

Data gathering, analyzing collected data, and contribution in designing research method: Khosro Keshavarz; Designing the research method, revising the manuscript, and final approval of results: Abbas Kebriaeezadeh, Seyed Moayed Alavian, and Shekoufeh Nikfar; designing the research method and revising the manuscript: Ali Akbari Sari and Farid Abedin Dorkoosh; Data gathering and drafting the manuscript: Maryam keshvari, Seyed Ali Malekhosseini, and Saman Nikeghbalian. All authors read and approved the final manuscript.

\section{References}

1. Kalantari H, Davari M, Akbari M, Hejazi SM, Kalantari M, Zakerin $S$, et al. The estimation of direct medical costs of treating patients with chronic hepatitis B and C in iran. Int J Prev Med. 2012;3(3):191-6.

2. Lok AS. Chronic hepatitis B. N Engl J Med. 2002;346(22):1682-3.

3. Alavian SM, Fallahian F, Lankarani KB. The changing epidemiology of viral hepatitis B in Iran. J Gastrointestin Liver Dis. 2007;16(4):403-6.

4. Zeng M, Mao Y, Yao G, Wang H, Hou J, Wang Y, et al. A double-blind randomized trial of adefovir dipivoxil in Chinese subjects with HBeAg-positive chronic hepatitis B. Hepatology. 2006;44(1):10816.

5. Lee WM. Hepatitis B virus infection. NEnglJMed.1997;337(24):173345.

6. Lai CL. Chronic hepatitis B in Hong Kong: immunization strategies for the control of hepatitis B virus infection. Hepat B Asian Pac Region. 1997;1:79-87.

7. Alavian SM. Hepatitis B virus infection in Iran; Changing the epidemiology. Arch Clin Infect Dis. 2010;5(1):51-61.

8. Lavanchy D. Hepatitis B virus epidemiology, disease burden, treatment, and current and emerging prevention and control measures. JViral Hepat. 2004;11(2):97-107.

9. Qirbi N, Hall AJ. Epidemiology of hepatitis B virus infection in the Middle East. East Mediterr Health J. 2001;7(6):1034-45.

10. Shahnaz S, Reza B. Risk factors in chronic hepatitis B infection: a case-control study. Hepat Mon. 2005;2005(4):109-15.

11. Nguyen VT, Law MG, Dore GJ. An enormous hepatitis B virus-related liver disease burden projected in Vietnam by 2025. Liver Int. 2008;28(4):525-31.

12. Alavian SM, Hajarizadeh B, Ahmadzad-Asl M, Kabir A, BagheriLankarani K. Hepatitis B Virus infection in Iran: A systematic review. Hepat Mon. 2008;8(4):281-94.

13. Lai CL, Yuen MF. The natural history of chronic hepatitis B.J Viral Hepat. 2007;14 Suppl 1:6-10.
14. McMahon BJ. Epidemiology and natural history of hepatitis B. Semin Liver Dis. 2005;25 Suppl 1:3-8.

15. Kavosi Z, Zare F, Jafari A, Fattahi MR. Economic burden of hepatitis B virus infection in different stages of disease; a report from southern iran. Middle East J Dig Dis. 2014;6(3):156-61.

16. Mehrazmay A, Alavian SM, Moradi-Lakeh M, Mokhtari Payam M, Hashemi-Meshkini A, Behnava B, et al. Cost-effectiveness analysis of adding low dose ribavirin to peginterferon alfa-2a for treatment of chronic hepatitis $\mathrm{C}$ infected thalassemia major patients in iran. Hepat Mon. 2013;13(9).

17. Keshavarz K, Kebriaeezadeh A, Meshkini AH, Nikfar S, Mirian I, Khoonsari H. Financial perspective of private pharmacies in Tehran (Iran); is it a lucrative business? Daru. 2012;20(1):62.

18. Tan SS, Rutten FF, van Ineveld BM, Redekop WK, Hakkaart-van Roijen L. Comparing methodologies for the cost estimation of hospital services. Eur J Health Econ. 2009;10(1):39-45.

19. Haghparast-Bidgoli H, Kiadaliri AA, Skordis-Worrall J. Do economic evaluation studies inform effective healthcare resource allocation in Iran? A critical review of the literature. Cost Eff Resour Alloc. 2014;12:15.

20. Ong SC, Lim SG, Li SC. How big is the financial burden of hepatitis B to society? A cost-of-illness study of hepatitis B infection in Singapore. J Viral Hepat. 2009;16(1):53-63.

21. Tu HAT, Woerdenbag HJ, Riewpaiboon A, Kane S, Le DM, Postma MJ, et al. Cost of Illness of Chronic Hepatitis B Infection in Vietnam. Value in Health Regional Issues. 2012;1(1):23-8.

22. Central Bank of the Islamic Republic of Iran.. The Rate Currency. 2013. Available from: http://www.cbi.ir/ExRates/rates_fa.aspx.

23. Nikfar S, Kebriaeezadeh A, Dinarvand R, Abdollahi M, Sahraian MA, Henry D, et al. Cost-effectiveness of different interferon beta products for relapsing-remitting and secondary progressive multiple sclerosis: Decision analysis based on long-term clinical data and switchable treatments. Daru. 2013;21(1):50.

24. Poorolajal J, Majdzadeh R. Prevalence of chronic hepatitis B infection in Iran: a review article. J Res Med Sci. 2009;14(4):249-58.

25. Iran Statistic Centre, editor. [updated 2015]; Available from: http://www.amar.org.ir.

26. Fazli ZFB, Fatemeh S, Abdi A, Pourhosseingholi MA, Taghinejad H. Studying of liver cancer mortality and morbidity burden in Iran. Sci I Ilam Univ Med Sci. 2012;4(20):117-22.

27. Babamahmoodi FB, Haghshenas M, Haghshenas M. Treatment of chronic hepatitis B virus infection. J Clin Excell. 2013;1(1):1-25.

28. Iran Government news Network. Iran budget law. 2013. Available from: http://www.dolat.ir.

29. Kowdley KV. The cost of managing chronic hepatitis B infection: a global perspective. J Clin Gastroenterol. 2004;38(10 Suppl 3):S132-3.

30. Hsieh CR, Kuo CW. Cost of chronic hepatitis B virus infection in Taiwan. J Clin Gastroenterol. 2004;38(10 Suppl 3):S148-52.

31. Li SC, Ong SC, Lim SG, Yeoh KG, Kwong KS, Lee V, et al. A cost comparison of management of chronic hepatitis B and its associated complications in Hong Kong and Singapore. J Clin Gastroenterol. 2004;38(10 Suppl 3):S136-43.

32. Yang BM, Kim CH, Kim JY. Cost of chronic hepatitis B infection in South Korea. J Clin Gastroenterol. 2004;38(10 Suppl 3):S153-7.

33. Nasiripour AA, Ghorbani Kalkhajeh S. The Challenges of Increasing Out of Pocket Payment in Healthcare System. Int J Healthcare, Healthc Equity. 2014;1(2)

34. Varmaghani M, Arab M, Zeraati $H$. The most important factors that patient choose public or private hospital. MSc thesis. 2008. 